\title{
Corporate Social Responsibility, Environmental Pollution, and Stock Market Reaction
}

\author{
Ya-Fang Wang ${ }^{\dagger}$ \\ Providence University, 200, Sec. 7, Taiwan Boulevard, Shalu Dist., Taichung City 43301, Taiwan
}

\begin{tabular}{l}
\hline ARTICLE INFO \\
\hline Article History \\
Received 05 March 2021; \\
Accepted 14 May 2021 \\
\hline JEL Classifications \\
M41
\end{tabular}

Keywords:

corporate social responsibility; environmental pollution; material information; stock market reaction \begin{abstract} Purpose:

This paper analyzes whether and how the environmental protection concern of corporate social responsibility companies affects market participants' perceptions by examining the nature and structure of corporate social responsibility companies.

Design/methodology/approach:

I begin constructing my sample by hand-collecting data related to the material information of environmental pollution issues and the list of corporate social responsibility companies from the Market Observation Post System, the Gre Tai Securities Market, and the companies' websites. The sample period began in 2007 because it was at that time that information related to corporate social responsibility activities became available. Then, I use the multivariate regression analysis to test research questions.

Finding:

Empirical findings indicate that a statistically significant relation between material pollution concerns of corporate social responsibility companies and their subsequent negative stock performance. But, when such corporate social responsibility companies have a complete mechanism or corporate governance environment to support corporate social responsibility engagements, they are less likely to receive the subsequent negative stock performance. After considering the corporate social responsibility foundation, there is no evidence of corporate social responsibility foundation supporting to modulate the negative shock of pollution concerns. However, empirical results seem to imply that market participants give a higher tolerance for the companies with corporate social responsibility foundation, and hence give them a slight negative impact on market returns.

Research limitations/implications:

Due to the costs of hand-collection, the sample comprised 7,707 firm-year observations associated with Taiwan listed companies over the period from 2007 to 2012.

Originality/value:

From a theoretical perspective, this study provides a new perspective on the effect of corporate social responsibility concerns by examining environmental pollution cases. From a practical perspective, this study examines a rarely discussed issue on the effect of corporate social responsibility concerns and identifies a corporate social responsibility concern factor (environmental pollution) that influences market returns.
\end{abstract}

\begin{abstract}
1. Introduction
In the recent decade, Corporate Social Responsibility (hereafter, CSR) has developed into a hot topic in the business environment receiving substantial attention from academics, corporations, governments and other bodies. The CSR is a complex interaction between companies and market participants, and it is also a subjective concept in which companies voluntarily integrate social, cultural and environmental concerns into their operations and into the interaction with their stakeholders (Cochran 2007; Dahlsrud 2008). The objective of CSR is fulfilling its obligation of the social and environmental responsibility, and hence, companies must comply with the CSR requirement for fulfilling the social responsibility of business and controlling the environmental pollution (Lyon and Maxwell 2008; Liu and Fong 2010). In the era of CSR, one of the crucial challenges for companies is to deal with the consequences of economic development.
\end{abstract}

Economic development brings not only economic improvement but also the pressure of environmental protection. Environmental protection is a matter of global concern and it is a crucial task for pollution preventing and controlling. Environmental pollution is one of the most crucial challenges for humans, and it has been formed the

${ }^{\dagger}$ Corresponding Author: Ya-Fang Wang

Email: yfwang2@pu.edu.tw

DOI: $10.25103 /$ ijbesar.141.03 
main concerns of the global health and economic system (World Bank 2016). Although sustainable environmental development appears to have economic justification, many serious problems are the direct result of economic development. Pollution from different industrial and activities deteriorates the environmental conditions, it not only threatens the human health condition but also impairs the economic growth. In general, pollution includes air, water, and other ecological forms of pollutions that are degrading the environment and depleting the natural resources. For example, World Health Organization (hereafter, WHO) reported that air pollution is one of the biggest global economic and health concerns and the most widely ignored one, and it kills an estimated seven million people worldwide every year (WHO 2016). The research report (WHO 2018) further reveals that 90\% of the world's population breathed polluted air in 2018, indicating that the air pollution is a major health problem of environmental pollution in many countries and the severity level of air pollution has attracted a lot of attention from the public.

In the era of CSR, companies require a careful consideration of how to deal with environmental pollution problems. Numerous prior studies (WHO 2006; WHO 2016; Cohen et al. 2017; WHO 2018; Liu et al. 2019) have been conducted on the effects of environmental pollution on human's health, however, no studies concerning CSR issues have attempted to explore whether and how market participants react environmental pollution. In this regard, the aim of this study is to investigate how CSR companies behave about the material information of environmental pollution (hereafter, MIEP) disclosure and how market participants react such particular type of voluntarily disclosures.

\section{Related literature and research question}

"Corporate Social Responsibility is the continuing commitment by business to behave ethically and contribute to economic development while improving the quality of life of the workforce and their families as well as of the local community and society at large (Holme and Watts 2000)."

According to the above CSR definition, companies have to ensure financial success and thus ensure that it brings a positive impact on the environment and society. In the era of CSR, the social responsibility not only plays a vital role in the business environment but also takes into consideration the relationship between business and society. Fulfilling social responsibility not only brings positive effects to the interaction of companies with the society but also bears significant cost and effort (Barnett and King 2008; Delmas and Montes-Sancho 2010; Gustafsson 2013; Dian et al. 2014). Thus, the cost-effectiveness evaluation of CSR performance also has become a subject of growing importance and debate in the social and economic development.

"WHO shows that 9 out of 10 people breathe air containing high levels of pollutants. WHO estimates that around 7 million people die every year from exposure to polluted air (WHO 2016, 2018)."

Environmental protection is one of the increasingly important tasks in CSR activities and communications, and it is relevant to human health. Thus, CSR companies are expected to preventing or controlling of environmental pollution to help improve environment quality. According to the WHO report (WHO 2016, 2018), environmental pollution has become one of the emerging environmental health problems over the world, and its negative effect is everywhere in the world. Hence, it is a difficult and arduous issue about how to reduce environmental pollution through CSR investments. In the era of CSR, CSR companies has faced the grand challenge that how to balance economic growth, social development, and environmental protection in their frameworks and activities.

In Taiwan, publicly listed companies must be legally required to disclose CSR reporting, and CSR reporting is driven by mandatory reporting regulations from the Taiwan Stock Exchange (hereafter, TSE). Mandatory CSR disclosures are more likely to become a formality or public-relation ploy. To advocate the importance of CSR and to encourage the substantive CSR activities, the Commonwealth Magazine annually selects outstanding CSR companies and confers them with the honor of CSR. An increasing number of Taiwanese listed companies start to engage in more socially responsible activities and use CSR reporting as a strategic management tool to communicate with market participants and shareholders. However, CSR-related governance mechanisms of Taiwanese listed companies are not yet well developed. In fact, most Taiwanese listed companies focus more on the framework of CSR reporting, and ignore the importance of CSR-related governance mechanism in fulfilling the CSR mission. Different from prior studies (Peloza 2006; Godfrey et al. 2009; Deng et al. 2013; Flammer 2013; Christensen 2016; Wans 2017 ; Lins et al. 2017; Bartov et al. 2021) which discussed the association between market reaction and CSR reporting from a disclosure perspective, this study considers a detailed discussion about the CSR-related governance mechanism to examine its impact on the economic consequences of CSR concern cases.

This raise a question that as to how are CSR companies viewing and dealing with environmental pollution problems? Whether are they voluntarily disclosing the material information of environmental pollution to the public? Whether and how are market participants reacting such material information of environmental pollution disclosures?

\section{Sample distribution}

I begin constructing my sample by hand-collecting data related to the material information of environmental pollution issues and the list of CSR companies from the Market Observation Post System (hereafter, MOPS), the Gre Tai Securities Market (hereafter, GTSM), and the companies' websites. The sample period began in 2007 because it was at that time that information related to CSR activities became available. Due to the costs of hand-collection, the sample 
comprised 7,707 firm-year observations associated with Taiwan listed companies over the period from 2007 to 2012. Company level data is obtained from the Taiwan Economic Journal (hereafter, TEJ) database.

Table 1 shows sample distribution by CSR activity status and environmental protection status. This table shows that 377 observations issued material information of environmental pollution (which account for $4.89 \%$ of the final sample), and 330 out of 337 are CSR observations (which account for $4.28 \%$ of the final sample). This result seems to be inconsistent with the argument that MIEP issued is less likely to be associated with CSR companies. A possible reason underlying this finding is that CSR companies take a proactive stance to fulfill their social responsibility behavior and minimize CSR risk. In the next section, this study will use multivariate analyses to explore this issue.

Table 1: Distribution CSR ${ }^{\mathrm{a}}$ and MIEP ${ }^{\mathrm{b}}$

\begin{tabular}{cccc}
\hline & Non-CSR Obs. & CSR Obs. & Total \\
\cline { 1 - 2 } Non-MIEP Obs. & 1,040 & 6,290 & 7,330 \\
MIEP Obs. & $(13.49 \%)$ & $(81.61 \%)$ & $(95.11 \%)$ \\
Total & 47 & 330 & 377 \\
\cline { 2 - 3 } & $(0.61 \%)$ & $(4.28 \%)$ & $(4.89 \%)$ \\
\hline
\end{tabular}

a CSR denotes companies engage in socially responsible activities relating to environmental, social, and governance issues.

${ }^{\mathrm{b}}$ MIEP denotes companies issue material information of environmental pollution.

Table 2 provides the sample distribution by year based on company's material information of environmental protection status. Over the sample period, there is a faster growth in number of MIEP in 2011. The underlying this finding is possible that Taiwan enacted the Air Pollution Control Act in 2011 for environmental protection and sustainability. To minimize the potentially CSR risk, this Act may prompt companies to voluntarily disclose MIEP.

Table 2: Distribution of MIEPa Obs. by Year

\begin{tabular}{cccc}
\hline Year & Number of Observations & Percent of Sample \\
\cline { 2 - 3 } 2007 & 44 & 51 & 11.67 \\
2008 & 56 & 14.53 \\
2009 & 66 & 17.51 \\
2010 & 92 & 24.40 \\
2011 & 68 & 18.04 \\
2012 & 377 & 100 \\
\hline
\end{tabular}

a MIEP denotes companies issue material information of environmental pollution.

As shown in Table 3, the sample distribution of MIEP issued was across a broad range of industries. Table 3 shows that electronics industries have the largest number of observations with 141 observations and about $37.40 \%$ of the MIEP sample. Chemicals and electric \& machinery industries also have the high percentages of observations in the MIEP sample $(19.10 \%$ and $17.24 \%$, respectively).

Table 3: Distribution of MIEPa Obs. by Industry

\begin{tabular}{|c|c|c|}
\hline Industry & Number of Observations & Percent of Sample \\
\hline Foods & 19 & 5.04 \\
\hline Plastics & 18 & 4.77 \\
\hline Textiles & 19 & 5.04 \\
\hline Electric \& Machinery & 65 & 17.24 \\
\hline Chemicals & 72 & 19.10 \\
\hline Cement & 15 & 3.98 \\
\hline Oil \& Gas & 2 & 0.53 \\
\hline Electronics & 141 & 37.40 \\
\hline Constructions & 9 & 2.39 \\
\hline Transportations & 7 & 1.86 \\
\hline Tourism & 1 & 0.27 \\
\hline Wholesale \& Retail & 3 & 0.80 \\
\hline Others & 6 & 1.59 \\
\hline Total & 377 & 100 \\
\hline
\end{tabular}

${ }^{a}$ MIEP denotes companies issue material information of environmental pollution.

Figure 1 illustrates and compares the performance of different company types (CSR, CSR\&MIEP, and CSR\&Non-MIEP). Figure 1 shows that the positive cumulative returns for the CSR\&MIEP group is relatively low in 
comparison to the CSR\&Non-MIEP group. Moreover, the negative cumulative returns for the CSR\&MIEP group is relatively less losses in comparison to the CSR\&Non-MIEP group.

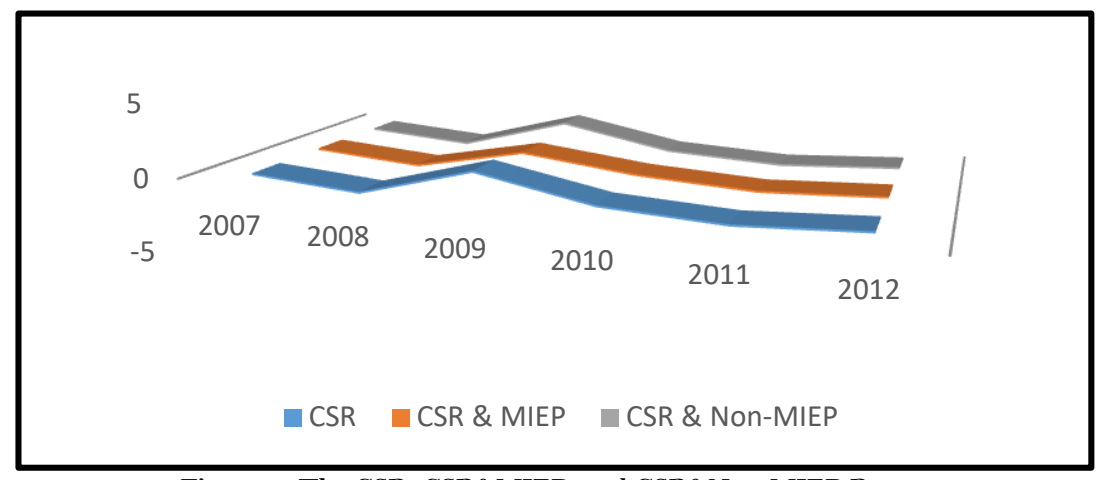

Figure 1: The CSR, CSR\&MIEP, and CSR\&Non-MIEP Return

\section{Results}

In each of primary research settings, I estimate the following ordinary least squares (OLS) regression to test research questions:

$$
\begin{aligned}
& \text { Return }_{i t}=\beta_{0}+\beta_{1} \text { CSR }_{i, t}+\sum \text { OLS Controls }_{i, t}+\varepsilon_{i, t .} \quad \text { (1) } \\
& \text { Return }_{i t}=\beta_{0}+\beta_{1} \text { MIEP }_{i, t}+\sum \text { OLS Controls }_{i, t}+\varepsilon_{i, t .} \text { (2) }
\end{aligned}
$$

In Equations (1) and (2), the dependent variable, Return, is market returns. The test variable of Equation (1), CSR, which is a dummy variable equal to 1 if companies engage in socially responsible activities relating to environmental, social, and governance issues; otherwise 0 . The test variable of Equation (1), MIEP, which is a dummy variable equal to 1 if companies issue material information of environmental pollution, otherwise 0 .

Table 4 reports empirical results on the relationship among environmental pollution, corporate social responsibility, and stock market reaction. As shown in Column (1), the coefficient of CSR is positively significant $(p<$ 0.01), indicating that companies practicing CSR activities are more likely to have high stock market return. Next, this study examines the effects of material information of environmental pollution associated with corporate social responsibility on the stock market reaction. This study further partitions research sample into two groups based on the CSR activity status: companies engaged in CSR activities $(n=6,620)$, and companies not engaged in CSR activities $(\mathrm{n}=1,087)$. As shown in Columns (2) and (3), the coefficient of CSR is only significant and negative $(p<$ 0.05) in Column (3), whereas it is insignificant in Column (2). These results indicate that a statistically significant relation between material CSR concerns and subsequent negative stock performance in the CSR sample. This clearly implies that unfavorable stock performance likely reflects market participants' concerns of CSR engagements. Additionally, the adjusted $\mathrm{R}^{2}$ in Column (1) is equal to $10.16 \%$, suggesting that approximately $10.16 \%$ of the variation in market returns is explained. When I partition the sample into two groups based on whether companies engage in CSR activities, the adjusted $\mathrm{R}^{2}$ is substantially increased in both CSR companies (48.08\%) and Non-CSR companies $(40.86 \%)$.

\begin{tabular}{|c|c|c|c|c|c|c|c|}
\hline \multirow[b]{3}{*}{ Variables $^{\mathrm{c}}$} & \multirow[b]{3}{*}{ Pred. Sign } & \multicolumn{2}{|c|}{$(1)$} & \multicolumn{2}{|c|}{$(2)$} & \multicolumn{2}{|c|}{ (3) } \\
\hline & & \multicolumn{2}{|c|}{ All Obs. } & \multicolumn{2}{|c|}{ Non-CSR Obs. } & \multicolumn{2}{|c|}{ CSR Obs. } \\
\hline & & Coef. & $t$-value ${ }^{\mathrm{d}}$ & Coef. & $t$-value & Coef. & $t$-value \\
\hline$\overline{C O N S T A N T}$ & & -2.8996 & $-7.68^{* * * *}$ & 0.1786 & 1.45 & 0.0485 & 0.90 \\
\hline$C S R$ & + & 0.3232 & $3.90^{* * * *}$ & & & & \\
\hline MIEP & - & & & -0.0227 & -0.30 & -0.0558 & $-2.01^{* *}$ \\
\hline YEAR & & \multicolumn{2}{|c|}{ Included } & \multicolumn{2}{|c|}{ Included } & \multicolumn{2}{|c|}{ Included } \\
\hline$I N D$ & & \multicolumn{2}{|c|}{ Included } & \multicolumn{2}{|c|}{ Included } & \multicolumn{2}{|c|}{ Included } \\
\hline Adj. $\mathrm{R}^{2}$ & & \multicolumn{2}{|c|}{$10.16 \%$} & \multicolumn{2}{|c|}{$40.86 \%$} & \multicolumn{2}{|c|}{$48.08 \%$} \\
\hline $\mathrm{N}$ & & \multicolumn{2}{|c|}{7.707} & \multicolumn{2}{|c|}{1,087} & \multicolumn{2}{|c|}{6,620} \\
\hline
\end{tabular}

Table 4: The Association among MIEPa ${ }^{\mathrm{a}} \mathbf{C S R}^{\mathrm{b}}$, and Return

a MIEP denotes companies issue material information of environmental pollution.

${ }^{\mathrm{b}}$ CSR denotes companies engage in socially responsible activities relating to environmental, social, and governance issues.

c The definition of the variables reported in this table are: RETURN = cumulative returns; $C S R=1$ if the company engaged in socially responsible activities relating to environmental, social, and governance issues, otherwise $0 ; M I E P=1$ if the company issued material information of environmental pollution, otherwise $0 ; \Upsilon E A R=$ fiscal year dummies; $I N D=$ dummy variables controlling for industries.

d Asterisks*******indicate significance at the 0.10 , 0.05, and 0.01 levels, respectively. One-tailed for directional expectations, and two-tailed for others.

CSR engagements need a complete mechanism in promoting the CSR activity and improving the CSR performance. Therefore, the organizational structure of CSR plays a significant role in performing the key responsibilities. This study further focuses on the organizational structure of CSR and investigates how market participants react CSR 
concerns about the material information of environmental pollution. Focusing on the CSR samples (companies engaged in CSR activities, $\mathrm{n}=6,620)$, Table 5 partitions the CSR samples into two groups and re-run the main regression analysis: CSR companies with a complete organizational system for CSR implementation $(\mathrm{n}=1,989)$, and CSR companies without a complete organizational system for CSR implementation $(n=4,631)$. As shown in Columns (1) and (2), the coefficient of MIEP is only significant and negative $(p<0.05)$ in Column $(1)$, whereas it is insignificant in Column (2). The empirical results reveal that CSR companies with the material information of environmental pollution are less likely to receive the subsequent negative stock performance, particularly when they have a complete mechanism to support CSR engagements. According these results, market participants seem to perceive the function of complete mechanism as a mediator role in modulating the CSR effectiveness and risks. The adjusted $\mathrm{R}^{2}$ is very high at least at $40 \%$ in both CSRORG and Non-CSRORG groups implying that MIEP explains a significant portion of the variability of market returns, no matter whether these CSR companies have a complete organizational system.

Table 5: MIEP ${ }^{\mathrm{a}}$ and Return: Considering the Organizational Structure of $\mathrm{CSR}^{\mathrm{b}}$

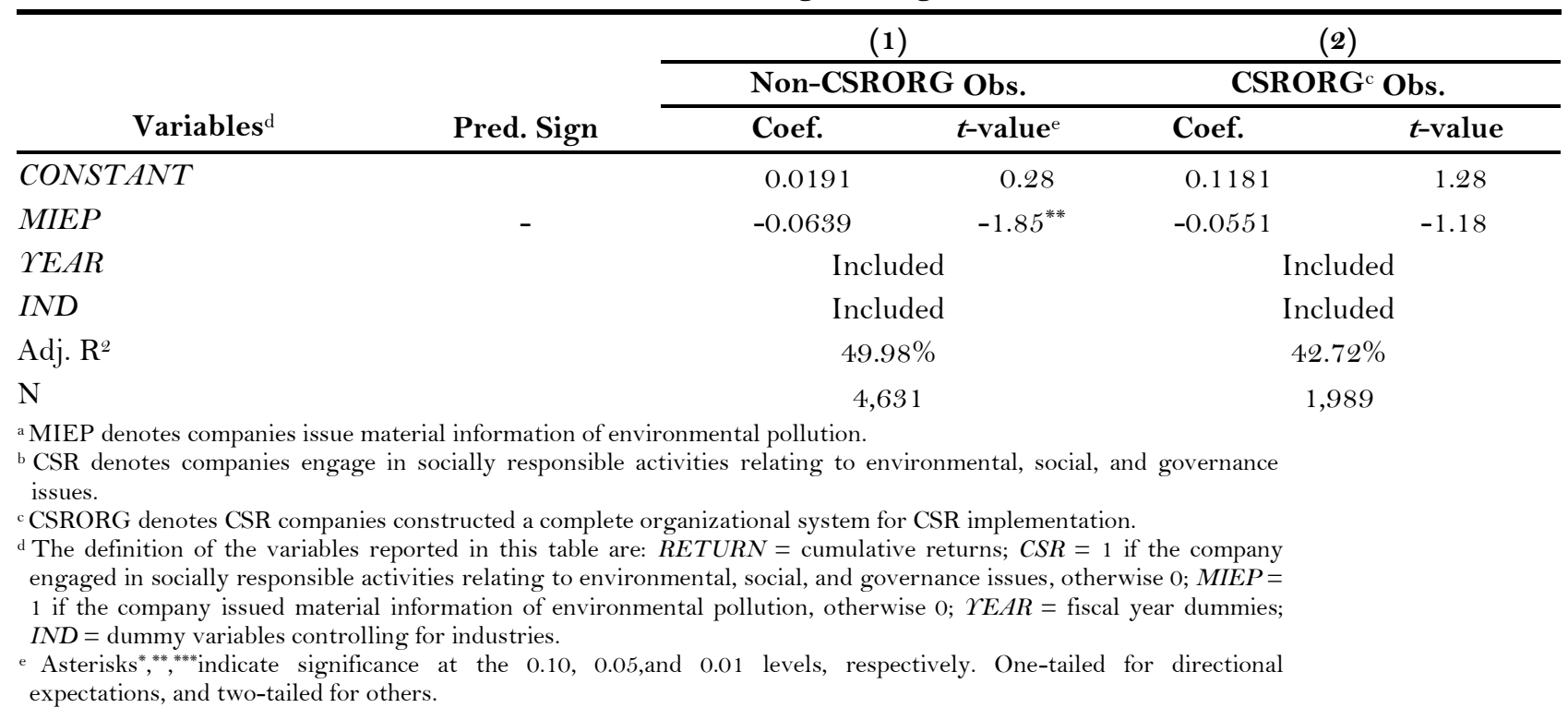

Corporate governance plays a positive and responsible role in determining the direction, control, and accountability of CSR engagements. This study further focuses on the corporate governance system of CSR and investigates whether and how corporate governance environment relates to CSR performance. Focusing on the CSR samples (companies engaged in CSR activities, $\mathrm{n}=6,620$ ), Table 6 partitions the CSR samples into two groups and re-run the main regression analysis: CSR companies with a comprehensive governance system for CSR implementation ( $\mathrm{n}=1,193$ ), and CSR companies without a comprehensive governance system for CSR implementation $(\mathrm{n}=5,427)$. As shown in Columns (1) and (2), the coefficient of MIEP is only significant and negative $(p<0.05)$ in Column (1), whereas it is insignificant in Column (2). The empirical results indicate a significant difference between the market reaction to CSR companies with and without the corporate governance system when CSR companies release the material information of environmental pollution. These results indicate that the governance environment of CSR matters, and thus reduce the impact of the negative shock. Empirical results also imply that market participants view a complete governance system can help CSR companies to appropriately deal with environmental protection problems, and thus, this study finds no evidence of a negative market reaction to such CSR companies. Table 6 should also be noted that the adjusted $\mathrm{R}^{2}$ is high in both CSRCG and Non-CSRCG groups $(35.80 \%$ and $50.14 \%$, respectively).

Table 6: MIEP ${ }^{\mathrm{a}}$ and Return: Considering the Corporate Governance System of CSR ${ }^{\mathrm{b}}$

\begin{tabular}{|c|c|c|c|c|c|}
\hline \multirow[b]{3}{*}{ Variables $^{\mathrm{d}}$} & \multirow[b]{3}{*}{ Pred. Sign } & \multicolumn{2}{|c|}{ (1) } & \multicolumn{2}{|c|}{ (2) } \\
\hline & & \multicolumn{2}{|c|}{ Non-CSRCG Obs. } & \multicolumn{2}{|c|}{ CSRCG $^{\mathrm{c}}$ Obs. } \\
\hline & & Coef. & $t$-value $e^{\mathrm{e}}$ & Coef. & $t$-value \\
\hline CONSTANT & & 0.0690 & 1.04 & 0.0354 & 0.51 \\
\hline MIEP & - & -0.0561 & $-1.81^{* *}$ & -0.0267 & -0.46 \\
\hline YEAR & & \multicolumn{2}{|c|}{ Included } & \multicolumn{2}{|c|}{ Included } \\
\hline$I N D$ & & \multicolumn{2}{|c|}{ Included } & \multicolumn{2}{|c|}{ Included } \\
\hline Adj. $\mathrm{R}^{2}$ & & \multicolumn{2}{|c|}{$50.14 \%$} & \multicolumn{2}{|c|}{$35.80 \%$} \\
\hline $\mathrm{N}$ & & \multicolumn{2}{|c|}{5,427} & \multicolumn{2}{|c|}{1,193} \\
\hline
\end{tabular}

a MIEP denotes companies issue material information of environmental pollution.

${ }^{\mathrm{b}} \mathrm{CSR}$ denotes companies engage in socially responsible activities relating to environmental, social, and governance issues. 
CSRCG denotes CSR companies developed a comprehensive governance mechanism in CSR system to implement CSR activities.

d The definition of the variables reported in this table are: RETURN = cumulative returns; CSR $=1$ if the company engaged in socially responsible activities relating to environmental, social, and governance issues, otherwise $0 ; M I E P=$ 1 if the company issued material information of environmental pollution, otherwise $0 ; Y E A R=$ fiscal year dummies; $I N D=$ dummy variables controlling for industries

Asterisks*, ${ }^{* * * * *}$ indicate significance at the $0.10,0.05$, and 0.01 levels, respectively. One-tailed for directional expectations, and two-tailed for others.

CSR foundation plays a key role in providing various resources and enhancing the CSR effectiveness. To examine the relationship between the market reaction of negative shock and CSR foundation, this study focuses on the CSR samples (companies engaged in CSR activities, $\mathrm{n}=6,620$ ) and further partitions the CSR samples into CSRFD and NonCSRFD groups: CSR companies with a foundation supporting CSR activities $(\mathrm{n}=1,001)$, and CSR companies without a foundation supporting CSR activities $(n=5,619)$. As shown in Columns $(1)$ and $(2)$ of Table 7 , the coefficients of MIEP are both significantly negative, indicating that market participants react unfavorably to CSR companies with the material information of environmental pollution, no matter whether they have foundation in promoting CSR practices. Notably, the coefficients of MIEP reported in these two columns are slightly different. The results seem to imply that market participants give a higher tolerance for the CSRFD group. Finally, I find similar results of the adjusted $\mathrm{R}^{2}$ in Columns (1) (48.08\%) and (2) (51.48\%) when I partition my sample into two groups based on whether these CSR companies have a foundation to support CSR activities.

Table 7: MIEP and Return: Considering the CSR $^{\mathrm{b}}$ Foundation

\begin{tabular}{|c|c|c|c|c|c|}
\hline \multirow[b]{3}{*}{ Variables $^{\mathrm{d}}$} & \multirow[b]{3}{*}{ Pred. Sign } & \multicolumn{2}{|c|}{ (1) } & \multicolumn{2}{|c|}{$(2)$} \\
\hline & & \multicolumn{2}{|c|}{ Non-CSRFD Obs. } & \multicolumn{2}{|c|}{ CSRFD $^{\mathrm{c}}$ Obs. } \\
\hline & & Coef. & $t$-value ${ }^{\mathrm{e}}$ & Coef. & $t$-value \\
\hline$\overline{C O N S T A N T}$ & & 0.0539 & 0.98 & -0.1488 & -0.73 \\
\hline MIEP & - & -0.05491 & $-1.73^{* * *}$ & -0.0884 & $-1.38^{*}$ \\
\hline$\Upsilon \mathscr{Y E A R}$ & & \multicolumn{2}{|c|}{ Included } & \multicolumn{2}{|c|}{ Included } \\
\hline$I N D$ & & \multicolumn{2}{|c|}{ Included } & \multicolumn{2}{|c|}{ Included } \\
\hline Adj. $\mathrm{R}^{2}$ & & \multicolumn{2}{|c|}{$48.08 \%$} & \multicolumn{2}{|c|}{$51.48 \%$} \\
\hline $\mathrm{N}$ & & \multicolumn{2}{|c|}{5,619} & \multicolumn{2}{|c|}{1,001} \\
\hline
\end{tabular}

a MIEP denotes companies issue material information of environmental pollution.

b CSR denotes companies engage in socially responsible activities relating to environmental, social, and governance issues.

'CSRFD denotes companies' CSR system included a foundation on the promotion of CSR activities.

$\mathrm{d}$ The definition of the variables reported in this table are: RETURN = cumulative returns; $C S R=1$ if the company engaged in socially responsible activities relating to environmental, social, and governance issues, otherwise $0 ; M I E P=$ 1 if the company issued material information of environmental pollution, otherwise $0 ; Y E A R=$ fiscal year dummies; $I N D=$ dummy variables controlling for industries

e Asterisks",*****indicate significance at the $0.10,0.05$, and 0.01 levels, respectively. One-tailed for directional expectations, and two-tailed for others.

\section{Discussion and conclusion}

This paper analyzes whether and how the environmental protection concern of CSR companies affects market participants' perceptions by examining the nature and structure of CSR companies. Empirical findings indicate that a statistically significant relation between CSR companies' material pollution concerns and their subsequent negative stock performance. But, when such CSR companies have a complete mechanism or corporate governance environment to support CSR engagements, they are less likely to receive the subsequent negative stock performance. After considering the CSR foundation, there is no evidence of CSR foundation supporting to modulate the negative shock of pollution concerns. However, empirical results seem to imply that market participants give a higher tolerance for the companies with CSR foundation, and hence give them a slight negative impact on market returns.

In my view, empirical findings have a number of implications for theory and practice. From a theoretical perspective, empirical findings extend CSR-related literature in two primary ways. First, this study provides evidence that market returns reflects the expectation of market participants for the future prospects and highlight that concerns of CSR engagements play an important role in affecting the perspective of the market and shareholders. Second, empirical findings provide a new perspective on the CSR concern effects by examining environmental pollution cases and add to the CSR-related literature on the important role that the governance environment of CSR companies plays in moderating the CSR effectiveness and risks in CSR concern cases.

From a practical perspective, this study examines a rarely discussed issue on the effect of CSR concern cases and identifies a CSR concern factor (environmental pollution) that influences market returns because such concern has negative effects on market participants' wealth, profitability and future prospects. Empirical results suggest that a completely CSR-related governance mechanism plays a key component of promoting CSR practices and moderating CSR concerns. Therefore, both regulators and policy-makers could encourage companies to set CSR-related objectives 
and governance mechanisms in order to provide greater transparency about CSR active information by which the market and shareholders can evaluate CSR effectiveness and influence on market returns.

\section{References}

Barnett, M. L. and A. A. King. 2008. Good fences make good neighbors: A longitudinal analysis of an industry self-regulatory institution. Academy of Management Journal, 51 1(6): 1150-1170.

Bartov, E., A. Marra, and F. Momenté. 2021. Corporate social responsibility and the market reaction to negative events: Evidence from inadvertent and fraudulent restatement announcements. The Accounting Review, 96(2): 81-106.

Cochran, P. L. 2007. The evolution of corporate social responsibility. Business Horizons, 50(6): 449-454.

Cohen, A. J., M. Brauer, R. Burnett, H. R. Anderson, J. Frostad, K. Estep, and V. Feigin. 2017. Estimates and 25-year trends of the global burden of disease attributable to ambient air pollution: an analysis of data from the Global Burden of Diseases Study 2015. The Lancet, 389(10082): 1907-1918.

Christensen, D. 2016. Corporate accountability reporting and high-profile misconduct. The Accounting Revierw, 91 (2): $377-399$.

Dahlsrud, A. 2008. How corporate social responsibility is defined: an analysis of 37 definitions. Corporate Social Responsibility and Environmental Management, 15: 1-13.

Delmas, M. A. and M. J. Montes-Sancho. 2010. Voluntary agreements to improve environmental quality: Symbolic and substantive cooperation. Strategic Management Journal, 31 1(6): 575- 601.

Deng, X. J., K. Kang, and B. S. Low. 2013. Corporate social responsibility and stakeholder value maximization: Evidence from mergers. Journal of Financial Economics, 1 10(1): 87-109.

Dian, M., D. Made, S. Djumahir, and G. S. Eko. 2014. CSR effect on market and financial performance. International Journal of Business and Management Invention, 3(1): 56-66.

Flammer, C. 2013. Corporate social responsibility and shareholder reaction: The environmental awareness of investors. Academy of Management Journal, 56(3): 758-781.

Godfrey, P., C. Merrill, and J. Hansen. 2009. The relationship between corporate social responsibility and shareholder value: An empirical test of the risk management hypothesis. Strategic Management Journal, 30 (4): 425-445.

Gustafsson, K. 2013. H\&M grabs more control of factories amid bangladesh unrest. Bloomberg, November 13.

Holme, R. and P. Watts. 2000. Corporate social responsibility: Making good business sense. World Business Council for Sustainable Development, January, 2000.

Lins, K. V., H. Servaes, and A. Tamayo. 2017. Social capital, trust, and firm performance: The value of corporate social responsibility during the financial crisis. Journal of Finance, 72(4): 1785-1824.

Liu, C., R. Chen, F. Sera, A. M. Vicedo-Cabrera, Y. Guo, S. Tong, and N. Valdes Ortega. 2019. Ambient particulate air pollution and daily mortality in 652 cities. New England Journal of Medicine, 381(8): 705-715.

Liu, H. and M. Fong. 2010. The corporate social responsibility orientation of Chinese small and medium enterprises. Journal of Business Systems, Governance and Ethics, 5(3): 33-50.

Lyon, T. P. and J. W. Maxwell. 2008. Corporate social responsibility and the environment: A theoretical perspective. Review of Environmental Economics and Policy, 1(1): 1-22.

Peloza, J. 2006. Using corporate social responsibility as insurance for financial performance. California Management Review, 48 (2): $52-72$.

Wans, N. 2017. Corporate social responsibility and market-based consequences of adverse corporate events: Evidence from restatement announcements. Journal of Accounting, Auditing and Finance, 35 (2): 231-262.

World Bank. 2016. The cost of air pollution: strengthening the economic case for action. Washington: World Bank Group.

World Health Organization. 2006. Air quality guidelines: global update 2005: particulate matter, ozone, nitrogen dioxide, and sulfur dioxide.

World Health Organization. 2016. Ambient Air Pollution: A global assessment of exposure and burden of disease. WHO Press: 3033.

World Health Organization. 2018. 9 out of 10 people worldwide breathe polluted air, but more countries are taking action. WHO, May 2, 2018. 